\title{
THE CORONA PANDAMIC IS A LESSON FOR HUMAN RACE: IN THE PERSPECTIVES OF VEDAS
}

\author{
REKHA NAUTIYAL \\ Department of Sanskrit, SDM Government PG College Doiwala, Dehradun, Uttarakhand \\ *Corresponding Author Email: rekha.uki112@gmail.com \\ Received: 20.10.2020; Revised: 28.11.2020; Accepted: 12.12 .2020 \\ CSociety for Himalayan Action Research and Development
}

\begin{abstract}
Not only India but the entire world is suffering from covid- 19 epedemic. It has a worst impact on the humanity due to lock down and closure of the entire industrial establishments. India was not only affected socio-economically but the most importantly due to health hazards. Lot of people lost their lives and the entire humanitarian system was shattered. Human beings were forced to adapt band live in the changed scenario. Present paper has a focus on the importance of Vedas, the ancient literature, on how to lead a systematic and managed life style and its importance in combating with current situation.
\end{abstract}

Keywords: COVID Pandamic, Nature, Pollution, Environment

\section{कोरोना महामारी मानव जाति के लिए एक सीख-वेदों के परिप्रेक्ष्य में \\ रेखा नौटियाल \\ श०दु०म०रा०स्ना०महा०ए डोईवाला, देहरादून}

\section{सारांश}

कोरोना महामारी से हमारा देश ही नहीं अपितु पूरा विश्व जूझ रहा है। पूरा विश्व कोरोना वायरस नामक एक ऐसे विकट समस्या से ग्रसित हो चुका है जिससे उभरना एक बहुत बडी चुनौती है। हमारा देश भी इससे अछूता नहीं रहा। कोरोना वायरस के कारण देशभर मे लॉकडाउन के कारण सभी फैक्ट्री, ऑफिस, मॉल्स, शिक्षण संस्थान तथा अन्य कारोबार आदि सब बन्द होने के कारण देश के जनजीवन पर बुरा असर पडा है। कोरोना काल ने भारत में आर्थिक, सामाजिक, राजनीतिक, यहाँ तक कि प्रत्येक व्यक्ति के शारीरिक एवं मानसिक स्वास्थ्य को भी प्रभावित किया है। इस संकट की घडी में सबसे अधिक वे लोग समस्याओं से जूझ रहे हैं जो मजदूरी, करते थे, जो फैक्ट्रियों में काम करते थे, छोटे-छोटे व्यवसाय करते थे तथा कृषि आदि करते थे। इन लोगों के सामने दो वक्त की रोटी की विकट समस्या आ गयी। जब छोटे स्तर पर काम बन्द हो गया तो इसका प्रभाव निश्चित रूप से हमारे देश की अर्थव्यवस्था पर भी पडा। इस कोरोना महामारी ने इन सभी समस्याओं को मनुष्य के सामने रखकर मानों मनुष्य को सोचने को मजबूर कर दिया कि हमें अपनी जीवन शेली मे सुधार एवं बदलाव की आवश्यकता है जिससे हम किसी भी विपरीत परिस्थितियों में भी अपने जीवन को चलाने में सक्षम हो सकें। हमारे वेदों मे प्राचीन समय से ही एक सुव्यवस्थित जीवन शैली वर्णित है जिसकी उपयोगिता आज हमारे लिए उपयोगी सिद्ध हो रही है। प्रस्तुत शोध पत्र का शीर्षक है "कोरोना महामारी मानव के लिए एक सीख - वेदों के परिप्रेक्ष्य में।"

कुंजी शब्द: कोरोना महामारी, प्रकृति, प्रदूशण, पर्यावरण । 


\section{प्रस्तावना}

आज के युग में हमारी नई पीढी ने अपना रहन-सहन, खान-पान, रीति-रिवाज सभी कुछ भुला के पाश्चात्य संस्कृति को अपना लिया है जो कि हम सब के लिए अत्यधिक नुकसानदायक है। हमारी संस्कृति वेदों को प्रमाणिक मानकर चलती है। हमारे वेदों में प्रातः सुबह उठने का विधान है जिससे हमारी दिनचर्या सुचारू रूप से संचालित होती थी। कोई भी रोग नहीं पकडता था। लेकिन आज की पीढी देर रात तक जगे रहना और सुबह को देर से उठने को अपनी जीवन शैली बना लिया है। इसके अतिरिक्त खानपान में भी नई पीढी दस कदम आगे निकल गयी है। आजकल सभी लोग मैगी, पिज्जा, बर्गर, चाउमिन, मोमो आदि जो मैदे से बनी खाने की चाजों को बहुत पसंद कर रहें हैं जिससे पाचन तंत्र कमजोर हो रहा है और रोगप्रतिरोधक क्षमता क्षीण हो जाती है। आज की युवा पीढी पाश्चात्य जीवन शैली से आकर्षित होकर अपने पैतृक घर एवं व्यवसायों कृषि आदि को छोडकर नौकरी की तलाश में शहरों की ओर पलायन कर रही हैं। जिसके कारण आज का युवा इस कोरोना काल में बेरोजगारी की मार झेल रहा है। जितने भी लोग होटल, मॉल्स, फैक्ट्रियों आदि में काम कर रहे थे उन लोगों के सामने रोजी-रोटी की समस्या आ खडी हुई है।

आज विश्व जिस कोरोना नामक महामारी का शिकार हो रहा है उसका मुख्य कारण मानव द्वारा प्रकृति के साथ छेड़छाड़ है। अपने स्वार्थ के लिए मानव ने जल, हवा को जहाँ प्रदूषित किया वहीं पृथ्वी का दोहन इतना अधिक किया कि उसकी क्षमता भी कम हो गयी। मानव की लाभ और लालसा का परिणाम है कि जल, थल, आकाश सब कुछ प्रभवित हो चुकें हैं। कोरोना महामारी स्पष्ट संकेत दे रही है कि अगर अब भी मानव ने प्रकृति के साथ छेडछाड जारी रखी तो उसका व उसकी भावी पीढियों का भविष्य अंधकारमय ही होगा। हवा और पानी के बिना जीवन के बारे में कोई कल्पना भी नहीं कर सकता और कटु सत्य यही है कि जल और हवा दोनों प्रभावित हो चुके। अब लॉकडाउन के दौरान जो तथ्य सामने आये हैं वे यही संकेत दे रहें हैं कि हवा और पानी दोनों शुद्ध रह सकते हैं अगर मानव चाहे तो। पिछले दिनों जालन्धर से धर्मशाला की पहाडियाँ साफ-साफ दिखाई दे रहीं थी और देहरादून से मसूरी की पहाडियाँ भी स्वच्छ दिखाई पड रही थी। आज की पीढी के लिए यह एक अजूबे से कम नहीं था जबकि बुजुर्गों का कहना है कि अतीत में यह बात आम थी। लॉकडाउन से पहले हवा की क्वालिटि 300 से लेकर 400 तक चला जाता था। दिल्ली, हरियाणा, पंजाब और हिमांचल प्रदेश में हवा के बढतें प्रदूषण के कारण समाज व सरकार चितिंत थे। आज लॉकडाउन के कारण हवा की क्वालिटि बहुत बेहतर हो गयी है। वैज्ञानिकों का मानना है कि हवा की शुद्धता से कम तीव्रता वाले भूकम्प की पहचान होने लगी है। वैज्ञानिकों के द्वारा अध्ययन करने पर पता वला है कि सभी मानवीय गतिविधियाँ ऐसे कम्पन पैदा करती हैं जिससे अच्छे उपकरणों से तीव्रता नापी जा सकती है। दुनिया के अनेक हिस्सों में जारी बंद की वजह से इन विकृतियों में कमी आई है। मानवीय गतिविधियों के कारण सांस्कृतिक व परिवेशीय शोर भी कम हो रहा है।

वैदिक परिप्रेक्ष्य में आज कोरोना महामारी के कारण इंसान की जीवन प्रणाली में अमूल चूल परिवर्तन आ रहे हैं। अब तक जो जीवन इंसान जी रहा था उसमें से कोई रास्ता निकलने वाला नहीं है इसलिए हमें अपनी जीवन शेली में बदलाव लाने की सख्त आवश्यकता है। भारतीय संस्कृति में निहित प्राचीनता, निरंतरता, धार्मिकसहिष्णुता, सार्वभौमिकता, वसुधैवकुटुम्बकम्, समन्वयवाद जैसे तत्व उसकी विशेषताओं को परिलक्षित करते हैं। मानव संस्कृति का सम्बन्ध ज्ञान, कर्म तथा रचना से है। हमारी भारतीय संस्कृति की बात करें तो इसका अतीत अत्यधिक गौरवपूर्ण है, हमारी संस्कृति विश्व की विभिन्न सभ्यताओं में अत्यधिक आदरपूर्ण स्थान प्राप्त है। ऐसे विकट समय में हमें अपनी वैदिक संस्कृति की ओर रूख करने की जरूरत है क्योंकि हमारे वेदों में कहा गया है-"सा संस्कृति : प्रथिमा विश्ववारा "जिसका अर्थ है कि संस्कृति विश्व के कल्याण के लिए है। वेदों में सर्वप्रथम पर्यावरण को महत्व दिया जाता गया है। वैदिक ऋषियों ने पर्यावरण के प्रति मानव को सचेत ही नहीं किया अपितु उसके संरक्षण के लिए प्रेरित भी किया। इसके लिए उसने पर्यावरण से जुडे सभी पदार्थों को देवत्व प्रदान कर उनके प्रति आदरभाव प्रकट कर उसे धार्मिक आस्था से जोडकर निरंतर संरक्षण और संवर्धन का मार्ग प्रशस्त किया $ं$ वेदों में पर्यावरण संरक्षण अर्थात् वायु, जल, पृथ्वी और आकाश के लिए विशेष सावधानी बरती गई। हमारा शरीर पाँच तत्वों- भूमी, आकाश, वायु, अग्नि, जल का मिश्रण है। इंसान ईश्वर की अनुपम कृति है। भारतीय मनीषियों ने पंच तत्वों के महत्व को समझा और यजुर्वेद में यह स्पष्ट है मानव का शरीर पृथ्वी, जल, अग्नि, वायु तथा आकाश इन पाँच 
तत्वों से बना है। अतः मनुष्य का यह परम कर्तव्य है कि मानव जीवन को सुरक्षित रखने के लिए पर्यावरण के सभी तत्वों को स्वच्छ रखना अत्यन्त आवश्यक है।

संस्कृतवाङ्मय में प्रकृति हमेशा पूजनीय रही है। भारतीय ऋषि प्राकृतिक भात्तियों की उपासना, प्राकृतिक शत्तियों के सन्तुलन, पर्यावरण की सुरक्षा एंव इसके स्थायित्व के लिए सदैव चिन्तनशील रहे है। पर्यावरण के सम्बन्ध में ऋषियों द्वारा की गई मंगलकामना इस प्रकार दर्शनीय है-

ओम द्यौः शान्तिरन्तरिक्ष थं शान्तिः पृथिवी शान्तिरापः शान्तिरोशधयः शान्ति। वनस्पतयः शान्तिर्विश्वे देवा: शन्तिर्त्रहम शान्तिः सर्व थं शान्तिः। शान्तिरेव शान्ति सा मा शान्तिरेधि।। ${ }^{1}$

अर्थात पृथिवी ही नही अपितु पृथिवी के ऊपर अन्तरिक्ष अनन्त आकाश में शान्ति स्थापित हो, पाताल भूगर्भ में शन्ति हो, वृक्षों में शन्ति हो, वनस्पति में शान्ति हो, औषधियों में शान्ति हो, जल आदि भी शान्त रहे।

भारतीय ऋषियों ने प्रकृति के साथ सभी प्राकृतिक शक्तियों को देवतुल्य माना है। प्राकृतिक शक्तियों में सूर्य को देवता माना गया है सूर्य के अभाव में पृथ्वी पर जीवन सम्भव नही है वैदिक ऋशियों द्धारा प्रार्थना की गई है कि सूर्य से हमारा अलगाव न हो इस सम्बन्ध मे 'न: सूर्यस्य संदृशे मा युयोथा' ${ }^{2}$ उपनिषदो में सूर्य को प्राण की संज्ञा दी गई है आदित्यो हश्वै प्राण: ${ }^{3}$ प्राणियो के लिए स्वच्छ वायु का सेवन कितना हितकर और लाभदायक है यह बात ऋग्वेद में सुस्पष्ट है-

\section{वात आ वातु भेषजं शंभु मयोभु नो हृदि। प्रण आयूंशि तारिशत् II $^{4}$}

ऋग्वेद मे शुद्व वायु को परम औषधि बताया गया है- यददो नो वात ते गृहेडमृतस्य निधिर्हितः। ततो नो देहि जीव से। $1^{5}$ वेदों में पर्यावरण शुद्वि के लिए अग्नि का स्थान बहुत ही महत्वपूर्ण है। अग्नि का कार्य है जलाना अर्थात जहॉ भी अशुद्वि, है प्रदूष्ण है, कीटाणु है, उनको नष्ट करना। अग्नि को सभी प्रदूषणकारी तत्वों को नष्ट करने वाला कहा गया है। ${ }^{6}$

जल स्नेह, रुप, रस तथा स्पर्श गुण वाला है। इसके शुद्ध सेवन से बल की वृद्वि, पवित्रता तथा अनेकों रोग दूर होते है। ${ }^{7}$ वेदो में जल को अमृतस्वरुप माना गया है ${ }^{8}$ पृथ्वी पर नदी, झरने, तालाब व समुद्र जल के प्रमुख स्रोत है। वर्तमान समय में पर्यावरण प्रदूषण की समस्या विश्व के सामने भयावह रुप धारण किये हुये खड़ी है। जल प्रदूषण, वायु प्रदूष्ण, मृदा प्रदूषण, रेडियोधर्मी प्रदूषण आदि का कारण मानव ही है। पारिवारिक सुख समृद्वि तथा वैभव का आधार पर्यावरण की शुद्धता है। अतः सम्पूर्ण विश्व के नागरिकों को इसकी महत्ता को समझना होगा, तभी हम अपनी आगे आने वाली पीढ़ी को एक स्वच्छ वातावरण प्रदान कर सकेंगे।

अर्थवेद में पृथिवीसूक्त राष्ट्र की शस्य स्यामला भूमि को सुन्दर व उत्कृष्ट बनाने की कामना की गई है-

विश्वंभरा वसुधानी प्रतिष्ठा हिरण्यवक्षा जगतो निवेशनी।

वैश्वानर बिभ्रती भूमिरग्निमिन्द्र ऋषभा द्रविणे नो दधातु । ${ }^{9}$

इस प्रकार से मानव के लिए कोरोना महामारी एक सीख है कि हमें अपने प्रकृति को नुकसान नहीं पहुँचाना है, बल्कि उसके संरक्षण एवं सवंर्धन के प्रति जागरूक रहना है जिससे इस तरह की महामारियों एवं आपदाओं से अपने देश एवं विश्व को बचाया जा सके।

सन्दर्भ ग्रन्थ सूची

1 शुक्ल यजुर्वेद

2 ऋग्वेद $2 / 33 / 1$

3 प्रश्नोपनिषद 115

4 ऋग्वेद $10 / 186 / 12$

5 ॠग्वेद $10 / 186 / 3$

6 ऋग्वेद $06 / 16 / 28$

7 अथर्ववेद $12 / 327$

8 ॠग्वेद $23 / 9$

9 अथर्ववेद $12 / 1 / 6$

10. समाचार एवं अनेक पत्र/पत्रिकाएं 